\title{
Simultaneous Measurement of Amino Acid Enantiomers in Aged Mouse Brain Samples by LC/MS/MS Combined with Derivatization Using $N^{\alpha}$-(5-Fluoro-2,4-dinitrophenyl)- L-leucinamide (L-FDLA)
}

\author{
Taiji Yamamoto ${ }^{1,+}$, Keisuke Yaku ${ }^{1,+}$ and Takashi Nakagawa ${ }^{1,2, * \text { (D) }}$ \\ 1 Department of Molecular and Medical Pharmacology, Faculty of Medicine, University of Toyama, \\ Toyama 930-0194, Japan; s1550102@ems.u-toyama.ac.jp (T.Y.); yaku@med.u-toyama.ac.jp (K.Y.) \\ 2 Research Center for Pre-Disease Science, University of Toyama, Toyama 930-0194, Japan \\ * Correspondence: nakagawa@med.u-toyama.ac.jp \\ + These authors contributed equally to this work.
}

Citation: Yamamoto, T.; Yaku, K.; Nakagawa, T. Simultaneous

Measurement of Amino Acid Enantiomers in Aged Mouse Brain Samples by LC/MS/MS Combined with Derivatization Using $N^{\alpha}$-(5-Fluoro-2,4-dinitrophenyl)-Lleucinamide (L-FDLA). Metabolites 2021, 11, 57. https://doi.org/ 10.3390/metabo11010057

Received: 21 December 2020

Accepted: 14 January 2021

Published: 15 January 2021

Publisher's Note: MDPI stays neutral with regard to jurisdictional claims in published maps and institutional affiliations.

Copyright: (c) 2021 by the authors. Licensee MDPI, Basel, Switzerland. This article is an open access article distributed under the terms and conditions of the Creative Commons Attribution (CC BY) license (https:// creativecommons.org/licenses/by/ $4.0 /)$.

\begin{abstract}
D-amino acids have distinct roles from their L-enantiomer. In particular, some D-amino acids function as agonists or antagonists of neuronal receptors and are involved in higher brain functions. Thus, it is important to precisely measure the levels of these amino acid enantiomers in cells and tissues. Various quantification methods have been developed for measurements of chiral amino acids. However, each method has advantages and disadvantages. Additionally, measuring the amino acid enantiomers in crude biological samples requires a higher selectivity. In this study, we developed a quantification method for amino acid enantiomers using derivatization with $N^{\alpha}$ (5-Fluoro-2,4-dinitrophenyl)-L-leucinamide (L-FDLA) followed by liquid chromatography-tandem mass spectrometry (LC/MS/MS) with a conventional reversed-phase column. We simultaneously identified 10 chiral amino acids. Furthermore, we applied this method to investigate murine tissue samples and examined the effect of aging on the amino acid levels in aged brain regions. We found that aging decreased the levels of both D-serine and D-aspartate in the hippocampus. In addition, D-Phenylalanine in the thalamus significantly increased with age. In conclusion, our method is suitable for the quantification of the D-amino acids in crude biological samples and may contribute to elucidating the biological roles of chiral amino acids.
\end{abstract}

Keywords: D-amino acid; LC/MS/MS; L-FDLA; aging; brain

\section{Introduction}

Amino acids are pivotal nutrients which serve as energy sources and building blocks for organisms. Twenty amino acids make up the mammalian proteins. They all (except glycine) have one or two chiral centers where four different functional groups or atoms are attached to the same carbon [1]. Therefore, each amino acid has two enantiomeric forms, denoted L- and D-amino acids. In mammals, although L-amino acids predominate, the D-enantiomers also exist and have biological functions in certain tissues such as the brain [2]. In particular, D-serine (D-Ser) and D-aspartate (D-Asp) are relatively abundant in the brain and have distinct roles from their L-enantiomers [3-5]. D-Asps were the first free D-amino acids identified in mammals, including humans, and are a precursor for $N$-methyl-D-aspartate (NMDA) [4,6-8]. D-Asp is abundant in the neonatal phase and its amount decreases after birth as the expression of D-aspartate oxidase increases [8-10]. D-Ser is another major free D-amino acid produced from L-Ser by serine racemase and is a co-agonist of the NMDA receptor that regulates neural functions [5]. Additionally, D-amino acids act on endocrine systems, thus might be important to maintain homeostasis [4,11]. D-Asp stimulates the production of several hormones in the pituitary and hypothalamus, and also promotes the production of testosterone in the testis [12-14]. Accordingly, the 
functions of D-amino acids have been increasingly investigated, and quantification methods have been developed to investigate their biological roles.

D-amino acid quantification methods require high sensitivity and selectivity because the abundance of D-amino acids in crude biological samples is low relative to L-amino acids. Numerous L- and D-amino acid quantification strategies have been reported. One of the approaches to detect D-amino acids is to employ enzymes that process D-amino acids but not L-amino acids [15]. D-amino acid oxidase (DAO) is often used for enzymatic detection of D-amino acids [15-17]. It converts basic and neutral D-amino acids to $\alpha$-keto acids in the presence of flavin adenine dinucleotide. Although enzymatic methods using DAO are relatively easy and cheap, it is difficult to distinguish each D-amino acid in crude biological samples. Thus, quantifying D-amino acids in crude biological samples requires analytical separation techniques. To achieve a chiral resolution of amino acid enantiomers, highperformance liquid chromatography (HPLC) is frequently employed [18-20]. However, conventional octadecylsilane (ODS) columns cannot separate free D- and L-amino acids because their retention times are identical [21]. Thus, chiral columns have been used for this purpose. They are packed with a chiral stationary phase that can separate the amino acid enantiomers [22,23]. However, these chiral columns have restrictions regarding mobile phase solvents and their durability is lower than that of conventional ODS columns [24]. Additionally, the detection of low amounts of D-amino acids requires baseline separation. Thus, liquid chromatography-mass spectrometry (LC/MS) is often employed, however several chiral columns are incompatible with LC/MS due to solvent restriction.

Another method for the indirect chiral resolution of amino acid enantiomers is chemical derivatization. Chemical derivatization allows separation on conventional ODS columns [25]. It also allows taking advantage of increased signals and low background noise to detect low amounts of D-amino acids. Several chiral derivatizing reagents have been developed. In 1984, Marfey developed the $N^{\alpha}$-(5-Fluoro-2,4-dinitrophenyl)-Lalaninamide (L-FDAA, also named Marfey's reagent) enabling the indirect chiral resolution of amino acid enantiomers and successfully separated the diastereomeric L- and D-amino acids by HPLC [26]. This Marfey's reagent is also compatible with LC/MS analysis [27]. Fujii et al. reported an advanced Marfey's reagent, $N^{\alpha}$-(5-Fluoro-2,4-dinitrophenyl)-Lleucinamide (L-FDLA) [28]. They showed that L-FDLA exhibited a higher sensitivity and separation for derivatized chiral amino acids compared with L-FDAA.

In this study, we used L-FDLA derivatization combined with LC/MS/MS to simultaneously quantify L- and D-amino acids in crude biological samples. Furthermore, we applied this method to examine the effect of aging on the amino acid levels in aged brain regions. We found that aging decreased the levels of both D-Ser and D-Asp in the hippocampus. In addition, D-Phenylalanine (D-Phe) in the aged thalamus significantly increased.

\section{Results}

2.1. Optimization of the Multiple Reaction Monitoring (MRM) Settings of LC/MS/MS for L-FDLA Derivatized Amino Acids

For this study, we prepared 10 commercially available D- and L-amino acids, including alanine (Ala), asparagine (Asn), aspartate (Asp), leucine (Leu), methionine (Met), proline (Pro), serine (Ser), glutamine (Gln), glutamate (Glu), and phenylalanine (Phe). Standard L-amino acids were derivatized with L-FDLA as described in the method section. The derivatization added approximately 294 Da to the molecular weight of the L-amino acid (Figure 1). We performed mass spectrometry in electrospray ionization (ESI) positive ion mode and determined the MRM settings using the direct infusion method. For all metabolites, we selected $[\mathrm{M}+\mathrm{H}]^{+}$as the precursor ion and confirmed the intensity using the selected ion monitoring (SIM) mode. We chose the $\mathrm{N}_{2}$ gas collision-induced fragment ion based on the criteria that it had the highest intensity. We optimized the fragmentor voltage and collision energy to achieve maximum MS intensity. We also confirmed the MRM settings for derivatized D-amino acid compounds, but all parameters were similar to L-amino acids derivatized with L-FDLA. 


\section{(c) \\ D- or L- amino acid \\ L-FDLA derivatized D- or L-amino acids}

Figure 1. Scheme of derivatization for amino acid enantiomers by $N^{\alpha}$-(5-Fluoro-2,4-dinitrophenyl)-L-leucinamide (LFDLA). L-FDLA-derivatized amino acids become diastereomeric and can be separated by a conventional reversed-phase high-performance liquid chromatography (HPLC) column.

\subsection{Detection of Derivatized Standard Compounds by LC/MS/MS}

Conventional reversed-phase HPLC columns cannot separate underivatized amino acid enantiomers. Thus, chiral or enantioselective derivatization is essential for the separation of D- and L-amino acid enantiomers. Besides, it is crucial to accurately identify Dand L-amino acids in crude biological samples. However, the molecular weight difference between Gln and Glu, or Asn and Asp, is approximately $1 \mathrm{Da}$, and the mass accuracy of a typical tandem mass spectrometer is around 0.5 Da. Thus, they are difficult to distinguish using a typical tandem mass spectrometer without performing HPLC column separation due to the detectable decimal mass limit, and the presence of natural isotopes, such as ${ }^{13} \mathrm{C}$. For the separation, we employed an MG3 column, a conventional reversed-phase ODS column, and performed chromatographic analysis using gradient elution with $5 \mathrm{mM}$ ammonium formate in water as mobile phase A and $100 \%$ of methanol as mobile phase B. The gradient elution went from $80 \%$ to $20 \%$ of mobile phase A. Using this analytical setting, we could distinguish the L- and D-enantiomers of all amino acids we tested (Figure 2). In all cases, L-enantiomers were eluted earlier than D-enantiomers. The retention time (RT) of L- and D-enantiomers differed by more than $0.6 \mathrm{~min}$. The RT of L-Glu and D-Glu were approximately 15.2 and $16.0 \mathrm{~min}$, respectively. Those of L-Gln and D-Gln were approximately 16.7 and $17.3 \mathrm{~min}$, respectively (Table 1 and Figure 2). Furthermore, we separated and distinguished Asp and Asn enantiomers (Table 1 and Figure 2). Using this method, we chromatographically separated most of the amino acid enantiomers.

Table 1. Multiple reaction monitoring (MRM) settings and retention time for the derivatized L- and D-amino acids. Standard L- and D-amino acids (AA) were derivatized with L-FDLA and measured by LC/MS/MS with positive ESI mode. The monoisotopic mass of standard amino acids before and after the derivatization (Da), precursor ion $(m / z)$, product ion $(m / z)$, collision energy $(\mathrm{eV})$, and retention time $(\mathrm{min})$ were shown.

\begin{tabular}{|c|c|c|c|c|c|c|c|}
\hline & \multicolumn{2}{|c|}{ Monoisotopic Mass } & \multirow[b]{2}{*}{$\begin{array}{l}\text { Precursor } \\
\text { Ion }(m / z)\end{array}$} & \multirow[b]{2}{*}{$\begin{array}{l}\text { Product Ion } \\
(\mathrm{m} / \mathrm{z})\end{array}$} & \multirow[b]{2}{*}{$\begin{array}{c}\text { Collision } \\
\text { Energy (eV) }\end{array}$} & \multicolumn{2}{|c|}{ Retention Time } \\
\hline & $\begin{array}{c}\text { Before } \\
\text { Derivatization }\end{array}$ & $\begin{array}{c}\text { After } \\
\text { Derivatization }\end{array}$ & & & & $\begin{array}{l}\text { L-AA } \\
(\min )\end{array}$ & $\begin{array}{l}\text { D-AA } \\
(\mathrm{min})\end{array}$ \\
\hline Ala & 89.0477 & 383.1441 & 384 & 339 & 6 & 17.0 & 18.9 \\
\hline Asn & 132.0535 & 426.1499 & 427 & 382 & 8 & 16.0 & 17.0 \\
\hline Asp & 133.0375 & 427.1339 & 428 & 383 & 6 & 14.0 & 14.9 \\
\hline Gln & 146.0691 & 440.1656 & 441 & 334 & 10 & 16.7 & 17.3 \\
\hline Glu & 147.0532 & 441.1496 & 442 & 397 & 8 & 15.2 & 16.0 \\
\hline Leu & 131.0946 & 425.1910 & 426 & 380 & 4 & 17.9 & 22.4 \\
\hline Met & 149.0510 & 443.1475 & 444 & 354 & 8 & 17.4 & 20.2 \\
\hline Phe & 165.0790 & 459.1754 & 460 & 415 & 8 & 17.7 & 21.0 \\
\hline Pro & 115.0633 & 409.1597 & 410 & 365 & 10 & 16.8 & 18.5 \\
\hline Ser & 105.0426 & 399.1390 & 400 & 355 & 6 & 16.4 & 17.1 \\
\hline
\end{tabular}



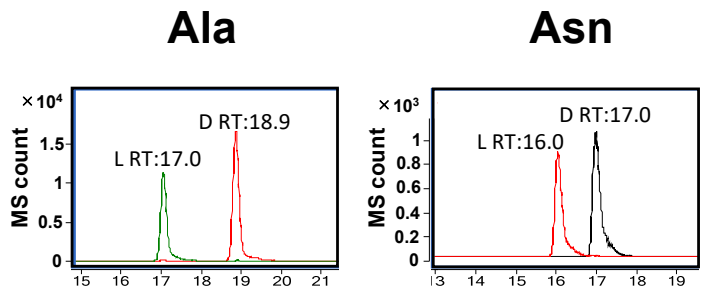

GIn

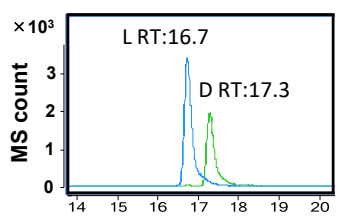

Met
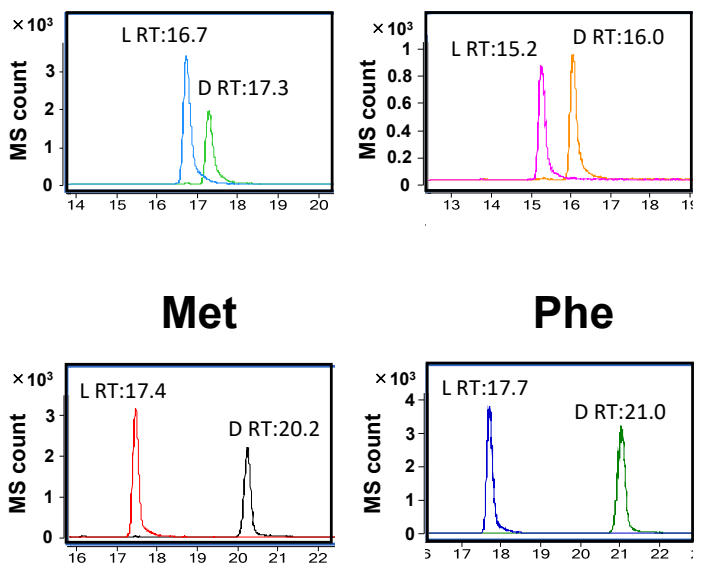

Asp

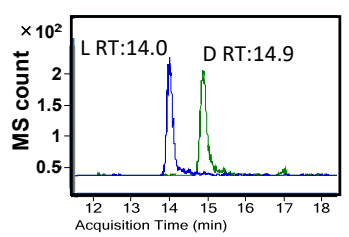

Leu

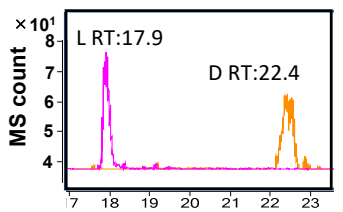

Pro

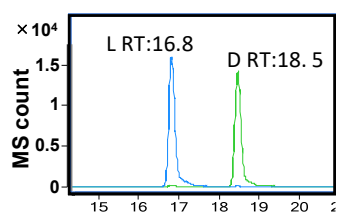

\section{Ser}

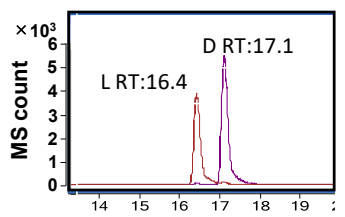

Figure 2. Chromatograms of standard compounds of derivatized L- and D-amino acids. Standard L- and D-amino acids were derivatized with L-FDLA and analyzed by LC/MS/MS. Representative MRM chromatograms of derivatized L- and D-amino acids are presented as merged to confirm the drift of retention time. In each panel, relative ion abundance (MS counts) versus retention time (min) are shown.

\subsection{Detection of Amino Acid Enantiomers in Biological Samples}

Compared with the pure standard compounds, crude biological samples, such as cell lysate and tissue homogenate, exhibit complex chromatograms. Some D-amino acids act as neurotransmitters and are abundant in brain tissues [29,30]. Thus, we attempted to detect amino acid enantiomers in murine brain cortex samples to validate our method. After euthanization, C57BL/6N mice brains were immediately collected and the cortex was separated. In these samples, we detected all the L-amino acids, but L-Leu had a bimodal peak at the expected retention time (Figure 3). In the brain, D-Ser is reportedly the D-amino acid with the highest concentration [7,31,32]. Accordingly, we found a prominent peak corresponding to D-Ser (Figure 4). We also observed peaks for D-Asn, D-Asp, D-Phe, D-Ala, and D-Pro. Although the peak of L-Glu was evident, that of D-Glu was difficult to detect. Similarly, D-Gln, D-Leu, and D-Met were impossible to detect. 
L-Ala

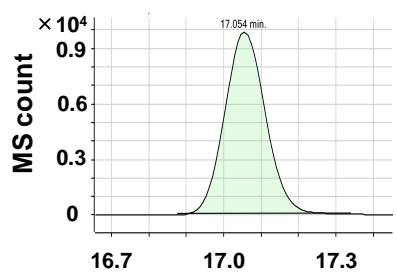

L-GIn

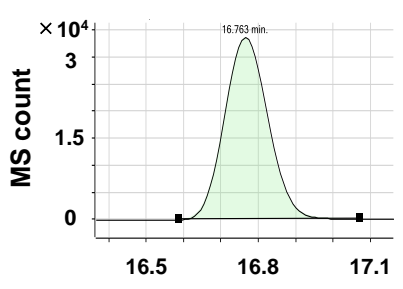

L-Met

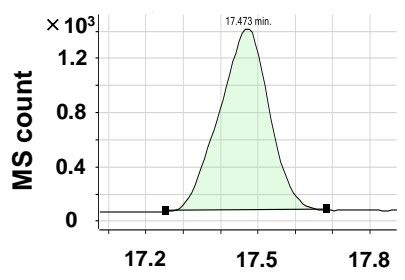

L-Ser

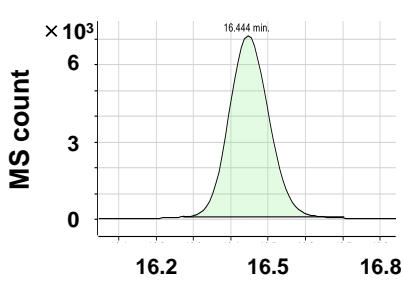

L-Asn

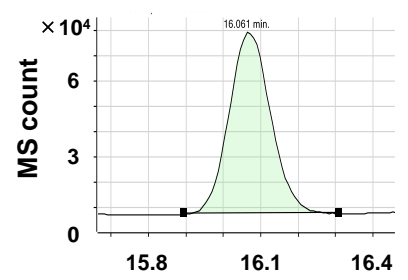

L-Glu

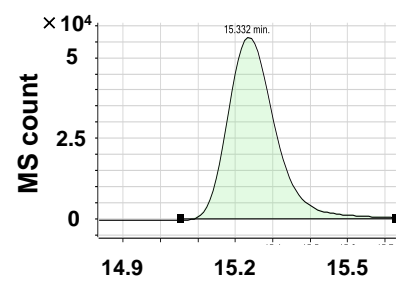

L-Phe

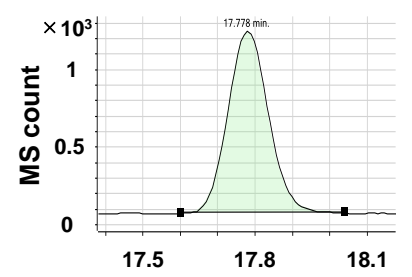

L-Asp

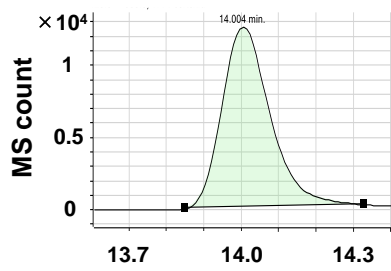

L-Leu

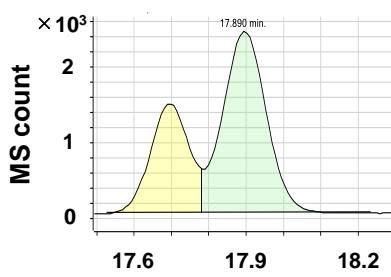

L-Pro

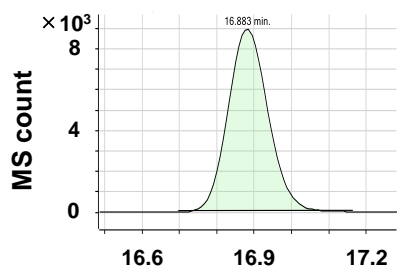

Figure 3. Chromatograms of derivatized L-amino acids in the murine cortex samples. Tissue samples were extracted from the cortices of 3-month-old mice. Representative MRM chromatograms of derivatized L-amino acids are shown. In each panel, relative ion abundance (MS counts) versus retention time (min) are shown. Integrated MS count (green) represents the amount of target molecules. 


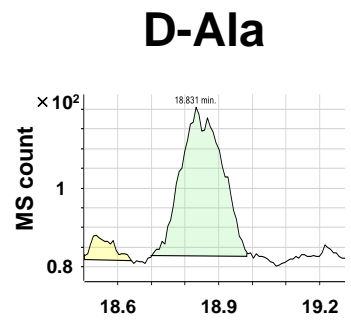

D-GIn

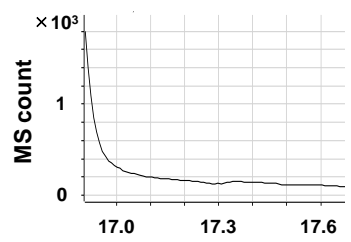

D-Met

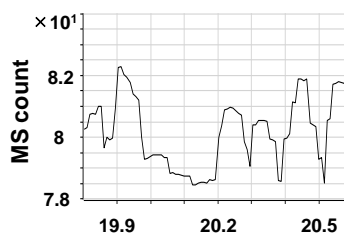

\section{D-Ser}

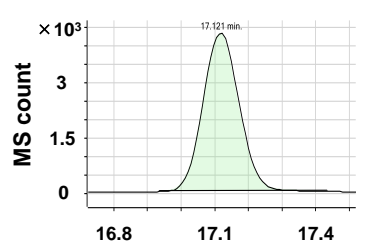

D-Asn

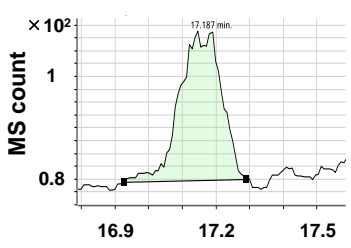

D-Glu

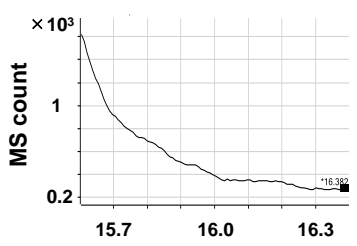

D-Phe

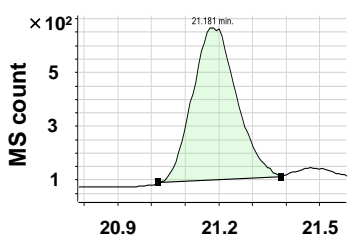

D-Asp

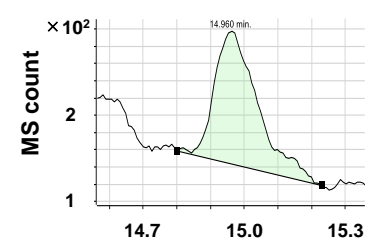

D-Leu

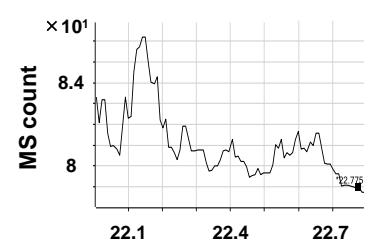

D-Pro

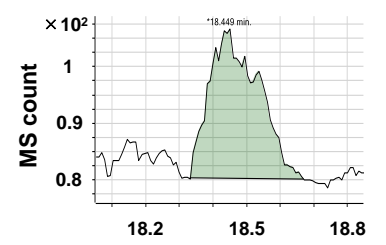

Figure 4. Chromatograms of derivatized D-amino acids in the murine cortex samples. Tissue samples were extracted from the cortices of 3-month-old mice. Representative MRM chromatograms of derivatized D-amino acids are shown. In each panel, relative ion abundance (MS counts) versus retention time (min) are shown. Integrated MS count (green) represents the amount of target molecules.

\subsection{Validation of the Absolute Quantification of Amino Acid Enantiomers}

To quantify the levels of D- and L-Asp, Asn, Ser, and Phe absolutely, we measured various concentrations of standard compounds using our method. We confirmed that the plots were linear within the concentrations that were tested (Figure 5). All tested compounds had $\mathrm{R}^{2}$ values $>0.98$. The equation coefficient in D-enantiomer is higher in Asn, Asp, and Ser, but lower in Phe. Although the sensitivity of LC/MS/MS was slightly lower for D-enantiomers, our method is suitable for the absolute quantification of both D- and L-enantiomers. 
L-Asn

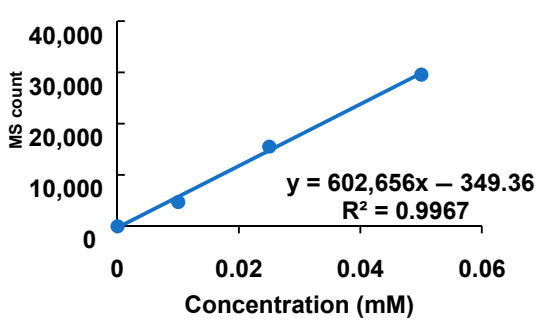

L-Asp

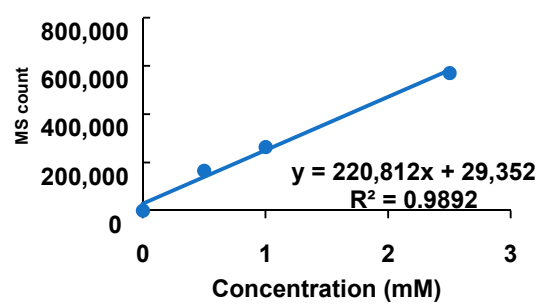

L-Phe

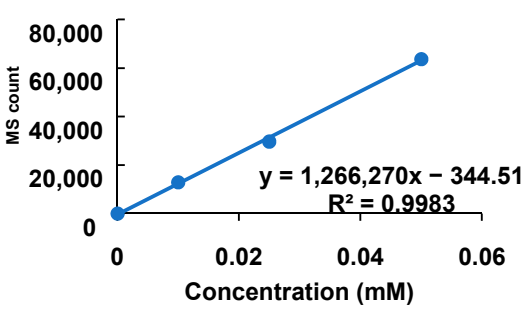

L-Ser

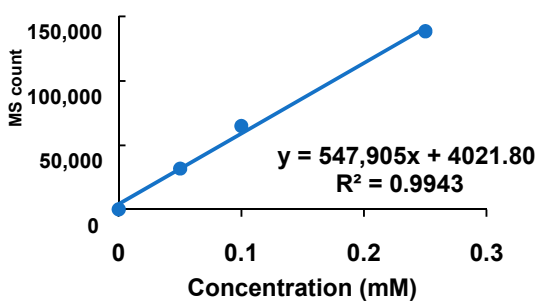

D-Asn

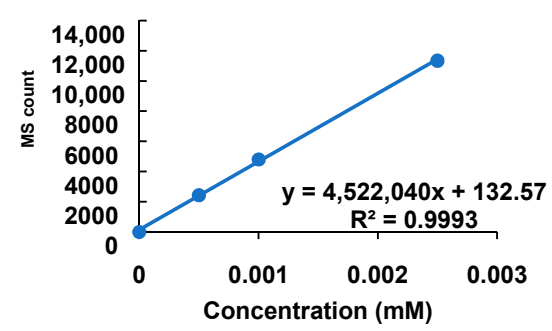

D-Asp

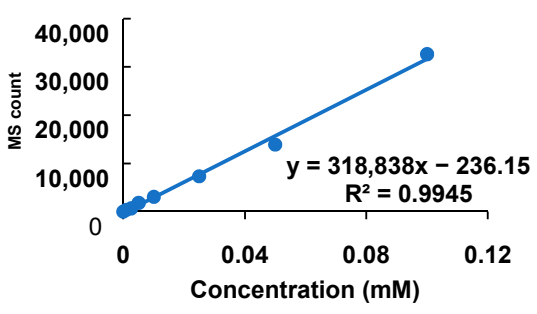

D-Phe

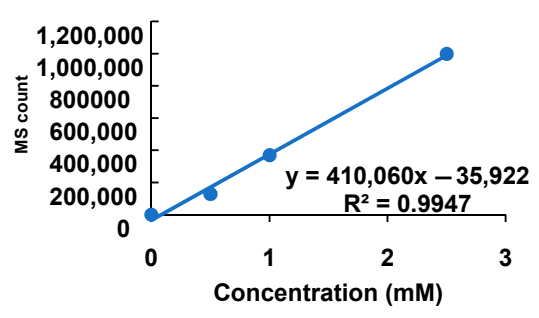

D-Ser

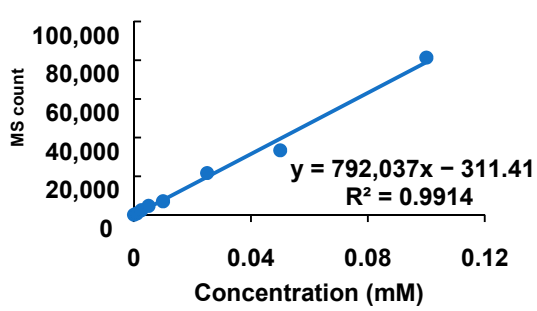

Figure 5. Standard curves of derivatized L- and D-amino acids. Trends of MS count to amino acid concentrations were calculated by measuring the several standard solutions. The $X$-axis represents concentrations of amino acids before being derivatized, and the $Y$-axis represents the integrated sum of the peak area from each chromatogram. The equations and $\mathrm{R}^{2}$ values of each plot are shown.

\subsection{Changes of Amino Acid Enantiomers in Aged Brains}

D-Ser is an endogenous ligand of the NMDA receptor and its decline is associated with synaptic plasticity and memory deficits in normal aging [33-35]. Indeed, it has been reported D-Ser levels decline with age in the hippocampus [33]. However, it is still unclear whether levels of other D-amino acid enantiomers decrease similarly. Here we applied our method to compare the levels of enantiomers of Asp, Asn, Ser, and Phe in the cerebellum, cortex, hippocampus, and thalamus of young and old animals. As previously reported, the levels of D-Ser decreased in the hippocampus with age (Table 2).

However, we observed no changes in the cerebellum, cortex, and thalamus. Additionally, the levels of D-Asp significantly declined in the aged hippocampus. Regarding L-enantiomers, L-Asn, L-Asp, and L-Ser also declined in the hippocampus with age. In the cerebellum and cortex, the levels of all of amino acid enantiomers were the same between young and aged mice. Interestingly, D-Phe, but not L-Phe, significantly increased with age 
in the thalamus. Thus, we established that our method was applicable to quantify amino acid enantiomers in crude biological samples.

Table 2. Absolute quantification of L- and D-amino acids in various brain regions from young and old mice. Metabolites were extracted from the cerebellum, cortex, hippocampus, and thalamus in young (3-month-old) and old (24-month-old) mice. After the derivatization with F-FDLA, the levels of L- and D-Asp, Asn, Ser, and Phe were absolutely quantified by LC/MS/MS. Amounts of L- and D-amino acids were calculated by using the standard curves obtained in Figure 5 . The data is represented as means \pm SD from young $(n=5)$ and old $(n=8)$ animals.

\begin{tabular}{|c|c|c|c|c|}
\hline & & Young & Old & \\
\hline \multirow{4}{*}{$\begin{array}{c}\mathrm{L}-\mathrm{Asn} \\
(\mu \mathrm{mol} / \mathrm{g} \text { tissue })\end{array}$} & Cerebellum & $0.107 \pm 0.018$ & $0.105 \pm 0.024$ & n.s. \\
\hline & Cortex & $0.135 \pm 0.038$ & $0.131 \pm 0.016$ & n.s. \\
\hline & Hippocampus & $0.150 \pm 0.015$ & $0.113 \pm 0.019$ & $p<0.05$ \\
\hline & Thalamus & $0.130 \pm 0.025$ & $0.122 \pm 0.022$ & n.s. \\
\hline \multirow{4}{*}{$\begin{array}{c}\text { D-Asn } \\
(\mu \mathrm{mol} / \mathrm{g} \text { tissue })\end{array}$} & Cerebellum & $0.000725 \pm 0.000111$ & $0.00100 \pm 0.00047$ & n.s. \\
\hline & Cortex & $0.000859 \pm 0.000246$ & $0.00103 \pm 0.00024$ & n.s. \\
\hline & Hippocampus & $0.00107 \pm 0.00006$ & $0.000893 \pm 0.000230$ & n.s. \\
\hline & Thalamus & $0.000625 \pm 0.000136$ & $0.000620 \pm 0.000222$ & n.s. \\
\hline \multirow{4}{*}{$\begin{array}{c}\mathrm{L}-\mathrm{Asp} \\
(\mu \mathrm{mol} / \mathrm{g} \text { tissue })\end{array}$} & Cerebellum & $11.3 \pm 2.3$ & $9.39 \pm 2.28$ & n.s. \\
\hline & Cortex & $7.02 \pm 2.04$ & $7.79 \pm 0.44$ & n.s. \\
\hline & Hippocampus & $9.54 \pm 1.04$ & $7.37 \pm 1.24$ & $p<0.05$ \\
\hline & Thalamus & $7.88 \pm 0.74$ & $6.73 \pm 1.51$ & n.s. \\
\hline \multirow{4}{*}{$\begin{array}{c}\text { D-Asp } \\
(\mu \mathrm{mol} / \mathrm{g} \text { tissue })\end{array}$} & Cerebellum & $0.0126 \pm 0.0053$ & $0.0147 \pm 0.0043$ & n.s. \\
\hline & Cortex & $0.0675 \pm 0.0253$ & $0.0608 \pm 0.0062$ & n.s. \\
\hline & Hippocampus & $0.0825 \pm 0.0130$ & $0.0560 \pm 0.0121$ & $p<0.05$ \\
\hline & Thalamus & $0.0422 \pm 0.0195$ & $0.0311 \pm 0.0060$ & n.s. \\
\hline \multirow{4}{*}{$\begin{array}{c}\text { L-Phe } \\
\text { ( } \mu \mathrm{mol} / \mathrm{g} \text { tissue) }\end{array}$} & Cerebellum & $0.107 \pm 0.009$ & $0.119 \pm 0.034$ & n.s. \\
\hline & Cortex & $0.0996 \pm 0.0231$ & $0.112 \pm 0.019$ & n.s. \\
\hline & Hippocampus & $0.129 \pm 0.012$ & $0.127 \pm 0.026$ & n.s. \\
\hline & Thalamus & $0.0966 \pm 0.0212$ & $0.101 \pm 0.032$ & n.s. \\
\hline \multirow{4}{*}{$\begin{array}{c}\text { D-Phe } \\
\text { ( } \mu \mathrm{mol} / \mathrm{g} \text { tissue) }\end{array}$} & Cerebellum & $0.287 \pm 0.096$ & $0.221 \pm 0.041$ & n.s. \\
\hline & Cortex & $0.246 \pm 0.059$ & $0.201 \pm 0.057$ & n.s. \\
\hline & Hippocampus & $0.207 \pm 0.069$ & $0.209 \pm 0.057$ & n.s. \\
\hline & Thalamus & $0.211 \pm 0.015$ & $0.241 \pm 0.015$ & $p<0.05$ \\
\hline \multirow{4}{*}{$\begin{array}{c}\text { L-Ser } \\
(\mu \mathrm{mol} / \mathrm{g} \text { tissue })\end{array}$} & Cerebellum & $0.983 \pm 0.114$ & $1.06 \pm 0.29$ & n.s. \\
\hline & Cortex & $1.31 \pm 0.34$ & $1.30 \pm 0.07$ & n.s. \\
\hline & Hippocampus & $1.56 \pm 0.09$ & $1.32 \pm 0.18$ & $p<0.05$ \\
\hline & Thalamus & $0.896 \pm 0.235$ & $0.819 \pm 0.139$ & n.s. \\
\hline \multirow{4}{*}{$\begin{array}{c}\text { D-Ser } \\
(\mu \mathrm{mol} / \mathrm{g} \text { tissue })\end{array}$} & Cerebellum & $0.0285 \pm 0.0158$ & $0.0211 \pm 0.0080$ & n.s. \\
\hline & Cortex & $0.609 \pm 0.156$ & $0.580 \pm 0.048$ & n.s. \\
\hline & Hippocampus & $0.646 \pm 0.041$ & $0.526 \pm 0.060$ & $p<0.01$ \\
\hline & Thalamus & $0.313 \pm 0.109$ & $0.279 \pm 0.036$ & n.s. \\
\hline
\end{tabular}




\section{Discussion}

In this study, we have developed a new absolute quantification method for amino acid enantiomers and validated its application to murine tissue samples. Many analytical methods have been reported for measurements of L-and D-amino acids. Separation before detection is essential for the accurate identification of chiral amino acids. Previously, liquid chromatographic methods using pre-column derivatization with chiral reagents have been developed for the indirect enantioseparation of D- and L-amino acids. These methods combined HPLC separation with diastereomerization using reagents such as L-FDAA [26], 1-(9-Fluorenyl)ethyl chloroformate [36], S-flunoxaprofen [37], or 1-(9-anthryl)-2-propyl chloroformate [38]. Additionally, $o$-phthaldialdehyde has been used in combination with $\mathrm{N}$-acetyl-L-cysteine or $\mathrm{N}$-tert-butyloxycarbonyl-L-cysteine [39,40]. Most of these methods used UV absorbance or fluorescence for the detection. However, these detection methods are less selective than MS detection. Therefore, derivatizing reagents compatible with MS are required for amino acid metabolomics. L-FDLA is a derivative of L-FDAA and gives more robust signals than L-FDAA in LC/MS [28]. However, we did not directly compare the detection sensitivity between L-FDAA- and L-FDLA-derivatized amino acids in this study, and further investigation is necessary to confirm the superiority of our method.

We applied our method to 10 pairs of amino acids. Our method worked for all the amino acids tested in this study when we measured each standard compound. On the other hand, detectable D-amino acids were limited in biological samples. We could not detect D-Gln, D-Glu, D-Leu, and D-Met, while we observed all the L-amino acids in the murine cortex. In particular, we could detect relatively prominent peaks of L-Glu and L-Gln in the cortex sample but failed to detect their D-enantiomers. Previous study also indicated that the ratio of L- and D-Glu and Gln is relatively large compared to other amino acids [41]. Previously, another group tried to map the regional distribution of D-amino acids in the brain, but they also failed to detect D-Asp, D-Ala, and D-Leu in the cerebrum, hypothalamus, and cerebellum in the 6-week-old rats [32]. Therefore, our method is more sensitive and applicable to the biological samples, at least for D-Asp and D-Ala. Regarding D-Ser, they also could determine its concentration in the cerebellum and hippocampus and reported their levels as 0.210 and $0.231 \mu \mathrm{mol} / \mathrm{g}$ tissue, respectively. In this study, we determined the levels of D-Ser in the hippocampus as $0.646 \mu \mathrm{mol} / \mathrm{g}$ tissue using 3-month-old mice. Thus, the sensitivity is almost comparable for D-Ser. Meanwhile, Inoue et al. successfully measured D-Leu in some brain regions including the cerebrum by combining 2D-HPLC with 4-Fluoro-7-nitrobenzofurazan derivatization [42]. Our fault in D-Leu detection may be attributed to ion suppression. Moreover, we got two peaks in L-Leu MRM possibly due to the incomplete separation of Leu and Ile. Therefore, the separation of these amino acids needs to be optimized by trying other columns and/or solvents.

Elucidating the distributions of D-amino acids in various tissues helps to clarify the physiological functions of D-amino acids. In the present study, we applied our method to determine the D-amino acid levels in various brain regions because of the importance of D-Ser and D-Asp in neuronal functions. We confirmed that the levels of both D-Ser and D-Asp decreased in the hippocampus with age. Besides, D-Phe significantly increased with age in the thalamus. In the brain, L-Phe is a competitive antagonist of the NMDA and AMPA receptors [43,44]. D-Phe is also an agonist of the niacin receptor 2 (NIACR2) [45]. However, the biological role of D-Phe is unknown. Thus, investigating the role of D-Phe and NIACR2 in the aged thalamus would of interest. Additionally, D-amino acids also exist in the heart, lungs, kidney, liver, thyroid, pancreas, adrenal gland, testes, and ovaries, but little is known about their importance in these tissues [14,16,46-49]. Interestingly, levels of D-amino acids have been reported as potential biomarkers of kidney function, aging, and diabetes [50]. Therefore, it is also important to test the applicability of our method in other tissues. 


\section{Materials and Methods}

\subsection{Reagents}

The standard compounds of L-Ala, L-Asn, L-Asp, L-Leu, L-Met, L-Pro, L-Ser, D-Asp, and D-Ser were purchased from Nacalai Tesque (Kyoto, Japan). L-Gln, L-Glu, L-Phe, DAla, D-Gln, D-Glu, D-Leu, D-Met, D-Phe, D-Pro, and L-FDLA were purchased from Tokyo Chemical Industry Co. Ltd. (Tokyo, Japan). D-Asn, LC/MS-grade ultrapure water and methanol, and ammonium formate were purchased from Wako Pure Chemical Industries Ltd. (Osaka, Japan).

\subsection{Animals}

Male C57BL/6N mice were obtained from Japan SLC Inc. (Hamamatsu, Japan) and were kept under a controlled temperature and standard light conditions (a 12:12 h lightdark cycle). They were fed a standard chow diet (CLEA Japan Inc., Tokyo, Japan) with free access to water for 3 or 24 months. All the animal experiments were approved by the Animal Experiment Committee of University of Toyama (Approval number A2017MED-11) and were performed in accordance with the Guidelines for the Care and Use of Laboratory Animals at the University of Toyama, which are based on international policies.

\subsection{Metabolite Extraction from Animal Tissues}

Metabolite extraction was described elsewhere [51]. Briefly, cerebellum, cortex, hippocampus, and thalamus were excised from 3- and 24-month-old mice. The tissues were immediately frozen in liquid nitrogen and kept at $-80{ }^{\circ} \mathrm{C}$ until use. Wet tissues weighing $30 \mathrm{mg}$ were ground in $1 \mathrm{~mL}$ of ice-cold $50 \%$ methanol- $50 \%$ water by using a multibeads shocker (Yasui Kikai, Osaka, Japan) under optimal conditions. The lysate was centrifuged, and the supernatant was collected into a new tube. Then, the same volume of chloroform was added to the supernatant. The mixture was centrifuged at $13,000 \times \mathrm{g}$ for $10 \mathrm{~min}$ at $4{ }^{\circ} \mathrm{C}$. The separated upper aqueous phase was transferred into a new tube and the same procedure was repeated one more time. Finally, the aqueous phase was dried and reconstituted in LC/MS-grade water.

\subsection{Derivatization of Amino Acids}

Standard amino acid compounds were derivatized by L-FDLA before the separation by HPLC. To derivatize amino acid compounds, $50 \mu \mathrm{L}$ of the standard solution were mixed with $10 \mu \mathrm{L}$ of $200 \mathrm{mM}$ sodium bicarbonate and $10 \mu \mathrm{L}$ of $1 \%$ L-FDLA in acetone. The mixture was incubated at $40{ }^{\circ} \mathrm{C}$ for $1 \mathrm{~h}$. After returning to room temperature, $930 \mu \mathrm{L}$ of $50 \%$ methanol- $50 \%$ water was added to the mixture. Subsequently, $10 \mu \mathrm{L}$ of the solution was mixed with $490 \mu \mathrm{L}$ of water followed by filtration using a $0.45 \mu \mathrm{m}$ Milex filter unit (Merck Millipore, Burlington, VT, USA). To derivatize tissue samples, $50 \mu \mathrm{L}$ of the reconstituted tissue samples mentioned above were processed as same as standard compounds. During these procedures, we keep samples in dark conditions.

\subsection{LC/MS/MS Condition}

Chromatographic analysis was performed by using an Agilent 6460 Triple Quad mass spectrometer that was coupled with an Agilent 1290 HPLC system. The detection of metabolites was conducted using positive ESI and multiple reaction monitoring (MRM) mode. The mass spectrometer settings were described previously [52]. To optimize MRM settings, standard compounds were prepared at a concentration of $1 \mu \mathrm{M}$ and $10 \mu \mathrm{L}$ of the solution was isocratically injected into the mass spectrometer having $50 \%$ of the mobile phase A ( $5 \mathrm{mM}$ ammonium formate in water) and $50 \%$ of the mobile phase B $(100 \%$ methanol) at a flow rate of $150 \mu \mathrm{L} / \mathrm{min} .[\mathrm{M}+\mathrm{H}]^{+}$ion was selected as a precursor ion for all amino acids. The collision energy to produce product ions was selected by checking the maximum intensity for each amino acid. The optimized MRM settings for the derivatized amino acids are listed in Table 1. The HPLC separation of the amino acids was performed by using an MG3 column $(2.0 \times 150 \mathrm{~mm}$, particle size of $3 \mu \mathrm{m}$, Osaka Soda, Osaka, Japan), 
having a gradient of mobile phase $\mathrm{A}$ ( $5 \mathrm{mM}$ ammonium formate in water) and mobile phase $B(100 \%$ of methanol) at a flow rate of $150 \mu \mathrm{L} / \mathrm{min}$. The programmed mobile phase gradient was as follows: $0-10 \mathrm{~min}, 20-80 \% \mathrm{~B} ; 10-15 \mathrm{~min}, 80 \% \mathrm{~B} ; 15-15.01 \mathrm{~min}, 80-20 \% \mathrm{~B}$. The column was equilibrated prior to sample injection, and the temperature of column oven was set at $40^{\circ} \mathrm{C}$.

\subsection{Quantification of Amino Acids}

To generate a standard curve of L- and D-amino acids, the standard compounds were diluted in water at concentrations adjusted for tissue contents. After derivatization, $10 \mu \mathrm{L}$ of the standard solution or tissue solution was separated and detected using the LC/MS/MS system. Each chromatographic area was integrated to calculate the amount of the compounds using the Mass Hunter Quantitative analysis software (Agilent Technologies, Santa Clara, CA, USA).

\subsection{Statistical Analysis}

The differences between the young and old tissues were analyzed by using an unpaired Student's $t$-test.

\section{Conclusions}

In conclusion, the absolute quantification of D-amino acid levels using LC/MS/MS combined with L-FDLA pre-derivatization is a useful and easy method for crude biological samples. Using this method, we found an alteration in levels of several D-amino acids during aging. Our method is more sensitive, at lease for several D-amino acids, compared with the methods previously reported. It is important to improve the sensitivity and to detect very low concentration D-amino acids in various tissues.

Author Contributions: T.Y., K.Y. and T.N. conceived and designed this project. T.Y. and K.Y. performed the experiments and analyzed the data. T.N. and K.Y. wrote the draft of manuscript. All authors have read and agreed to the published version of the manuscript.

Funding: This work was supported by the President Fund from University of Toyama to T.N. JSPS KAKENHI (Grant Number 20K20655 to T.N., 18K17921 to K.Y.) also partly supported this work.

Institutional Review Board Statement: All the animal experiments were approved by the Animal Experiment Committee of University of Toyama (Approval number A2017MED-11) and were performed in accordance with the Guidelines for the Care and Use of Laboratory Animals at the University of Toyama, which are based on international policies.

Informed Consent Statement: Not applicable.

Data Availability Statement: The data presented in this study are available in the article.

Acknowledgments: We are grateful to Tomomi Kubo (University of Toyama) for the husbandry care of mice. We also thank to Hisashi Mori (University of Toyama) and Nakagawa lab members for helpful discussion.

Conflicts of Interest: The authors declare no conflict of interests.

\section{References}

1. Genchi, G. An overview on D-amino acids. Amino Acids 2017, 49, 1521-1533. [CrossRef] [PubMed]

2. Seckler, J.M.; Lewis, S.J. Advances in D-Amino Acids in Neurological Research. Int. J. Mol. Sci. 2020, 21, 7325. [CrossRef] [PubMed]

3. Hashimoto, A.; Nishikawa, T.; Hayashi, T.; Fujii, N.; Harada, K.; Oka, T.; Takahashi, K. The presence of free D-serine in rat brain. FEBS Lett. 1992, 296, 33-36. [CrossRef]

4. Usiello, A.; Di Fiore, M.M.; De Rosa, A.; Falvo, S.; Errico, F.; Santillo, A.; Nuzzo, T.; Chieffi Baccari, G. New Evidence on the Role of D-Aspartate Metabolism in Regulating Brain and Endocrine System Physiology: From Preclinical Observations to Clinical Applications. Int. J. Mol. Sci. 2020, 21, 8718. [CrossRef]

5. Ploux, E.; Freret, T.; Billard, J.M. D-serine in physiological and pathological brain aging. Biochim. Biophys. Acta Proteins Proteom. 2021, 1869, 140542. [CrossRef] 
6. Man, E.H.; Sandhouse, M.E.; Burg, J.; Fisher, G.H. Accumulation of D-aspartic acid with age in the human brain. Science 1983, 220, 1407-1408. [CrossRef]

7. Fisher, G.H.; D'Aniello, A.; Vetere, A.; Padula, L.; Cusano, G.P.; Man, E.H. Free D-aspartate and D-alanine in normal and Alzheimer brain. Brain Res. Bull. 1991, 26, 983-985. [CrossRef]

8. Dunlop, D.S.; Neidle, A.; McHale, D.; Dunlop, D.M.; Lajtha, A. The presence of free D-aspartic acid in rodents and man. Biochem. Biophys. Res. Commun. 1986, 141, 27-32. [CrossRef]

9. Van Veldhoven, P.P.; Brees, C.; Mannaerts, G.P. D-Aspartate oxidase, a peroxisomal enzyme in liver of rat and man. Biochim. Biophys. Acta Gen. Subj. 1991, 1073, 203-208. [CrossRef]

10. Punzo, D.; Errico, F.; Cristino, L.; Sacchi, S.; Keller, S.; Belardo, C.; Luongo, L.; Nuzzo, T.; Imperatore, R.; Florio, E.; et al. Age-Related Changes in D-Aspartate Oxidase Promoter Methylation Control Extracellular D-Aspartate Levels and Prevent Precocious Cell Death during Brain Aging. J. Neurosci. 2016, 36, 3064-3078. [CrossRef]

11. Chieffi Baccari, G.; Falvo, S.; Santillo, A.; Di Giacomo Russo, F.; Di Fiore, M.M. D-Amino acids in mammalian endocrine tissues. Amino Acids 2020, 52, 1263-1273. [CrossRef] [PubMed]

12. D'Aniello, A.; Di Fiore, M.M.; Fisher, G.H.; Milone, A.; Seleni, A.; D'Aniello, S.; Perna, A.F.; Ingrosso, D. Occurrence of D-aspartic acid and N-methyl-D-aspartic acid in rat neuroendocrine tissues and their role in the modulation of luteinizing hormone and growth hormone release. FASEB J. 2000, 14, 699-714. [CrossRef] [PubMed]

13. Di Fiore, M.M.; Santillo, A.; Falvo, S.; Chieffi Baccari, G.; Venditti, M.; Di Giacomo Russo, F.; Lispi, M.; D’Aniello, A. Sex hormone levels in the brain of D-aspartate-treated rats. C R. Biol. 2018, 341, 9-15. [CrossRef] [PubMed]

14. Santillo, A.; Falvo, S.; Chieffi, P.; Burrone, L.; Chieffi Baccari, G.; Longobardi, S.; Di Fiore, M.M. D-aspartate affects NMDA receptorextracellular signal-regulated kinase pathway and upregulates androgen receptor expression in the rat testis. Theriogenology 2014, 81, 744-751. [CrossRef]

15. Molla, G.; Piubelli, L.; Volontè, F.; Pilone, M.S. Enzymatic detection of D-amino acids. Methods Mol. Biol. 2012, 794, 273-289. [CrossRef]

16. Nagata, Y.; Akino, T.; Ohno, K. The presence of free D-amino acids in mouse tissues. Experientia 1989, 45, 330-332. [CrossRef]

17. Hinkkanen, A.; Decker, K. Enzymatic determination of several D-amino acids using luminol-mediated chemiluminescence. Hoppe Seylers Z. Physiol. Chem. 1983, 364, 1549-1553. [CrossRef]

18. Buck, R.H.; Krummen, K. High-performance liquid chromatographic determination of enantiomeric amino acids and amino alcohols after derivatization with o-phthaldialdehyde and various chiral mercaptans. Application to peptide hydrolysates. $J$. Chromatogr. 1987, 387, 255-265. [CrossRef]

19. Brückner, H.; Westhauser, T.; Godel, H. Liquid chromatographic determination of D- and L-amino acids by derivatization with o-phthaldialdehyde and $\mathrm{N}$-isobutyryl-L-cysteine. Applications with reference to the analysis of peptidic antibiotics, toxins, drugs and pharmaceutically used amino acids. J. Chromatogr. A 1995, 711, 201-215. [CrossRef]

20. Okuma, E.; Abe, H. Simultaneous determination of D- and L-amino acids in the nervous tissues of crustaceans using precolumn derivatization with (+)-1-(9-fluorenyl)ethyl chloroformate and reversed-phase ion-pair high-performance liquid chromatography. J. Chromatogr. B Biomed. Appl. 1994, 660, 243-250. [CrossRef]

21. Ishii, C.; Akita, T.; Mita, M.; Ide, T.; Hamase, K. Development of an online two-dimensional high-performance liquid chromatographic system in combination with tandem mass spectrometric detection for enantiomeric analysis of free amino acids in human physiological fluid. J. Chromatogr. A 2018, 1570, 91-98. [CrossRef] [PubMed]

22. Hyun, M.H.; Jin, J.S.; Lee, W. Liquid chromatographic resolution of racemic amino acids and their derivatives on a new chiral stationary phase based on crown ether. J. Chromatogr. A 1998, 822, 155-161. [CrossRef]

23. Teixeira, J.; Tiritan, M.E.; Pinto, M.M.M.; Fernandes, C. Chiral Stationary Phases for Liquid Chromatography: Recent Developments. Molecules 2019, 24, 865. [CrossRef]

24. Lämmerhofer, M. Chiral recognition by enantioselective liquid chromatography: Mechanisms and modern chiral stationary phases. J. Chromatogr. A 2010, 1217, 814-856. [CrossRef] [PubMed]

25. Ilisz, I.; Aranyi, A.; Péter, A. Chiral derivatizations applied for the separation of unusual amino acid enantiomers by liquid chromatography and related techniques. J. Chromatogr. A 2013, 1296, 119-139. [CrossRef]

26. Marfey, P. Determination of D-amino acids. II. Use of a bifunctional reagent, 1,5-difluoro-2,4-dinitrobenzene. Carlsberg Res. Commun. 1984, 49, 591. [CrossRef]

27. Ayon, N.J.; Sharma, A.D.; Gutheil, W.G. LC-MS/MS-Based Separation and Quantification of Marfey's Reagent Derivatized Proteinogenic Amino Acid DL-Stereoisomers. J. Am. Soc. Mass Spectrom. 2019, 30, 448-458. [CrossRef]

28. Fujii, K.; Ikai, Y.; Oka, H.; Suzuki, M.; Harada, K.-i. A Nonempirical Method Using LC/MS for Determination of the Absolute Configuration of Constituent Amino Acids in a Peptide: Combination of Marfey's Method with Mass Spectrometry and Its Practical Application. Anal. Chem. 1997, 69, 5146-5151. [CrossRef]

29. Papouin, T.; Ladépêche, L.; Ruel, J.; Sacchi, S.; Labasque, M.; Hanini, M.; Groc, L.; Pollegioni, L.; Mothet, J.P.; Oliet, S.H. Synaptic and extrasynaptic NMDA receptors are gated by different endogenous coagonists. Cell 2012, 150, 633-646. [CrossRef]

30. Topo, E.; Soricelli, A.; Di Maio, A.; D'Aniello, E.; Di Fiore, M.M.; D'Aniello, A. Evidence for the involvement of D-aspartic acid in learning and memory of rat. Amino Acids 2010, 38, 1561-1569. [CrossRef]

31. Suzuki, M.; Imanishi, N.; Mita, M.; Hamase, K.; Aiso, S.; Sasabe, J. Heterogeneity of D-Serine Distribution in the Human Central Nervous System. ASN Neuro 2017, 9, 1759091417713905. [CrossRef] [PubMed] 
32. Hamase, K.; Homma, H.; Takigawa, Y.; Fukushima, T.; Santa, T.; Imai, K. Regional distribution and postnatal changes of D-amino acids in rat brain. Biochim. Biophys. Acta 1997, 1334, 214-222. [CrossRef]

33. Billard, J.M. D-Serine in the aging hippocampus. J. Pharm. Biomed. Anal. 2015, 116, 18-24. [CrossRef] [PubMed]

34. Potier, B.; Turpin, F.R.; Sinet, P.M.; Rouaud, E.; Mothet, J.P.; Videau, C.; Epelbaum, J.; Dutar, P.; Billard, J.M. Contribution of the D-Serine-Dependent Pathway to the Cellular Mechanisms Underlying Cognitive Aging. Front. Aging Neurosci. $2010,2,1$. [CrossRef]

35. Junjaud, G.; Rouaud, E.; Turpin, F.; Mothet, J.P.; Billard, J.M. Age-related effects of the neuromodulator D-serine on neurotransmission and synaptic potentiation in the CA1 hippocampal area of the rat. J. Neurochem. 2006, 98, 1159-1166. [CrossRef]

36. Einarsson, S.; Josefsson, B.; Möller, P.; Sanchez, D. Separation of amino acid enantiomers and chiral amines using precolumn derivatization with (+)-1-(9-fluorenyl)ethyl chloroformate and reversed-phase liquid chromatography. Anal. Chem. 1987, 59, 1191-1195. [CrossRef]

37. Langguth, P.; Spahn, H.; Merkle, H.P. Fluorescence assay for small peptides and amino acids: High-performance liquid chromatographic determination of selected substrates using activated S-flunoxaprofen as a chiral derivatizing agent. J. Chromatogr. 1990, 528, 55-64. [CrossRef]

38. Thorsén, G.; Engström, A.; Josefsson, B. Enantiomeric determination of amino compounds with high sensitivity using the chiral reagents (+)- and (-)-1-(9-anthryl)-2-propyl chloroformate. J. Chromatogr. A 1997, 786, 347-354. [CrossRef]

39. Aswad, D.W. Determination of D- and L-aspartate in amino acid mixtures by high-performance liquid chromatography after derivatization with a chiral adduct of o-phthaldialdehyde. Anal. Biochem. 1984, 137, 405-409. [CrossRef]

40. Brückner, H.; Wittner, R.; Godel, H. Automated enantioseparation of amino acids by derivatization with o-phthaldialdehyde and n-acylated cysteines. J. Chromatogr. 1989, 476, 73-82. [CrossRef]

41. Weatherly, C.A.; Du, S.; Parpia, C.; Santos, P.T.; Hartman, A.L.; Armstrong, D.W. D-Amino Acid Levels in Perfused Mouse Brain Tissue and Blood: A Comparative Study. ACS Chem. Neurosci. 2017, 8, 1251-1261. [CrossRef] [PubMed]

42. Inoue, T.; Hamase, K.; Morikawa, A.; Zaitsu, K. Determination of minute amounts of D-leucine in various brain regions of rat and mouse using column-switching high-performance liquid chromatography. J. Chromatogr. B Biomed. Sci. Appl. 2000, 744, $213-219$. [CrossRef]

43. Glushakov, A.V.; Dennis, D.M.; Morey, T.E.; Sumners, C.; Cucchiara, R.F.; Seubert, C.N.; Martynyuk, A.E. Specific inhibition of N-methyl-D-aspartate receptor function in rat hippocampal neurons by L-phenylalanine at concentrations observed during phenylketonuria. Mol. Psychiatry 2002, 7, 359-367. [CrossRef] [PubMed]

44. Glushakov, A.V.; Dennis, D.M.; Sumners, C.; Seubert, C.N.; Martynyuk, A.E. L-phenylalanine selectively depresses currents at glutamatergic excitatory synapses. J. Neurosci. Res. 2003, 72, 116-124. [CrossRef]

45. Irukayama-Tomobe, Y.; Tanaka, H.; Yokomizo, T.; Hashidate-Yoshida, T.; Yanagisawa, M.; Sakurai, T. Aromatic D-amino acids act as chemoattractant factors for human leukocytes through a G protein-coupled receptor, GPR109B. Proc. Natl. Acad. Sci. USA 2009, 106, 3930-3934. [CrossRef]

46. Ariyoshi, M.; Katane, M.; Hamase, K.; Miyoshi, Y.; Nakane, M.; Hoshino, A.; Okawa, Y.; Mita, Y.; Kaimoto, S.; Uchihashi, M.; et al. (D)-Glutamate is metabolized in the heart mitochondria. Sci. Rep. 2017, 7, 43911. [CrossRef]

47. Topo, E.; Fisher, G.; Sorricelli, A.; Errico, F.; Usiello, A.; D’Aniello, A. Thyroid hormones and D-aspartic acid, D-aspartate oxidase, D-aspartate racemase, $\mathrm{H} 2 \mathrm{O} 2$, and ROS in rats and mice. Chem. Biodivers. 2010, 7, 1467-1478. [CrossRef]

48. Hashimoto, A.; Nishikawa, T.; Oka, T.; Hayashi, T.; Takahashi, K. Widespread distribution of free D-aspartate in rat periphery. FEBS Lett. 1993, 331, 4-8. [CrossRef]

49. Lee, C.J.; Qiu, T.A.; Sweedler, J.V. D-Alanine: Distribution, origin, physiological relevance, and implications in disease. Biochim. Biophys. Acta Proteins Proteom. 2020, 1868, 140482. [CrossRef]

50. Kimura, T.; Hamase, K.; Miyoshi, Y.; Yamamoto, R.; Yasuda, K.; Mita, M.; Rakugi, H.; Hayashi, T.; Isaka, Y. Chiral amino acid metabolomics for novel biomarker screening in the prognosis of chronic kidney disease. Sci. Rep. 2016, 6, 26137. [CrossRef]

51. Yaku, K.; Okabe, K.; Gulshan, M.; Takatsu, K.; Okamoto, H.; Nakagawa, T. Metabolism and biochemical properties of nicotinamide adenine dinucleotide (NAD) analogs, nicotinamide guanine dinucleotide (NGD) and nicotinamide hypoxanthine dinucleotide (NHD). Sci. Rep. 2019, 9, 13102. [CrossRef] [PubMed]

52. Yaku, K.; Okabe, K.; Nakagawa, T. Simultaneous measurement of NAD metabolome in aged mice tissue using liquid chromatography tandem-mass spectrometry. Biomed. Chromatogr. 2018, 32, e4205. [CrossRef] [PubMed] 